\title{
Laparoscopic pancreaticoduodenectomy in pancreatic cancer: Our initial experience
}

\author{
Hüseyin Ayhan Kayaoğlu, Hacı Murat Çaycı, Umut Eren Erdoğdu, Evren Dilektașlı, Mehmet Emrah Bayam, Hasan Çantay
}

\section{ABSTRACT}

Cite this paper as:

Kayaoğlu HA, Çaycı HM, Erdoğdu UE, Dilektaşıı, Bayam ME, Çantay H. Laparoscopic pancreaticoduodenectomy in pancreatic cancer: Our initial experience. Turk J Surg 2018; 34(4): 323-326.

Clinic of General Surgery, Bursa Yüksek Ihtisas Training and Research Hospital, Bursa, Turkey

\section{Corresponding Author} Hacı Murat Çaycı e-mail:hmurat.cayci@gmail.com

Received: 14.01.2016 Accepted: 16.03.2016 Available Online Date: 03.01.2018

(C) Copyright 2018 by Turkish Surgical Association

Available online at www.turkjsurg.com
Pancreas cancer is an important cause of mortality worldwide. It has no particular symptoms, and may cause different complaints according to tumor diameter and localization. Local invasion may develop in the short term and distant metastasis may occur in vascular structures in its neighborhood. That's why, resectability rates are low at the time of diagnosis with a negative effect on survival rates. Minimally invasive surgery is being increasingly implemented in pancreas lesions owing to the positive short-term oncologic results of the technique in many other procedures. Traditionally, conventional open surgery is performed in pancreatic head tumors. As laparoscopic resection of pancreatic head cancer has serious technical difficulties and requires advanced laparoscopic experience, minimal invasive attempts in this field have not yet reached sufficient acceptance worldwide. Besides the fact that laparoscopic pancreaticoduodenectomy may provide sufficient short-term oncologic results that are comparative with open surgery, it can be implemented in selected patients in centers with advanced laparoscopic resection capacity. In this case series, we aimed to present our experience of laparoscopic pancreaticoduodenectomy in pancreatic head cancer patients.

Keywords: Minimal invasive, pancreas, laparoscopy, cancer

\section{INTRODUCTION}

Pancreas cancer displays an aggressive character with a tendency to rapid invasion of vascular structures around itself, early distant metastasis, and rapid local recurrence. The five-year survival rate in pancreas ductal adenocarcinomas is reported as 6-10\% (1). Effective oncologic resection offers the only potentially curative treatment option for this disease (2). However, only $15-20 \%$ of patients with pancreas cancer have resectable disease at the time of admission (2).

Minimal invasive surgery is being applied more frequently than conventional surgical operations due to achievement of satisfactory oncologic results, and decreases in postoperative pain, narcotic analgesic usage, and length of hospital stay (3). Initially, application of laparoscopy in pancreas surgery was limited to benign or premalignant lesions such as cyst drainage or enucleation. This was followed by radical resections on selected patients with malignant diseases, and the first laparoscopic pancreaticoduodenectomy was defined in 1994 (4). Difficulty in detecting pancreas cancer patients in the resectable period, rapid invasion of major vascular structures, challenges in pancreatic resection and anastomosis restrict the use of laparoscopic operations in this field. Experience in advanced laparoscopic techniques is essential for radical pancreatic resections. The effectiveness of minimally invasive surgery in pancreatic cancer will be shown with the detection of local recurrence and survival rates in long-term follow-ups. Discussions about the utility of laparoscopic approaches or that they produce better results than open surgery still continue because the studies are still limited to case series or few randomized controlled and short-term follow-up studies. In this report, we aimed to present five patients with pancreas head cancer who underwent laparoscopic pancreaticoduodenectomy in our clinics and to review the literature.

\section{CASE PRESENTATION}

Data of 5 patients who underwent laparoscopic pancreaticoduodenectomy in Bursa Yüksek Ihtisas Training and Research Hospital between January $1^{\text {st }}$ to December $31^{\text {st }}, 2015$ due to pancreatic head tumor were evaluated retrospectively. All patients were informed about the laparoscopic operation, and their informed consents were taken. Demographic data of the patients, presence of comorbidity, ASA scores (American Society of Anesthesiologists), preoperative bilirubin and tumor marker levels, diameters of the common bile duct and pancreatic duct, duration of the operations, tumor diameter, presence of lymph node metastasis, morbidity and mortality rates were evaluated.

The presence of regional or distant metastasis, possible invasion to the portal vein, superior mesenteric vein (SMV), and superior mesenteric artery (SMA) and diameter of the tumor were evaluated with multi- 
slice computed tomography (CT) in the preoperative period in all patients. Routine blood tests and carcinoembryonic antigen (CEA) and carbohydrate antigen 19-9 (CA 19-9) levels were studied preoperatively. Preoperative biliary drainage (percutaneous or surgical) was not performed in any patient with high levels of total and direct bilirubin levels. Enteral supplement and liquid diet were given in preoperative period.

Laparoscopic pancreaticoduodenectomy operations were performed by the same surgeon. The patient was operated in reverse Trendelenburg and Lloyd-Davis positions. A 10-12 $\mathrm{mm}$ telescope trocar was placed in the abdomen below the umbilicus following pneumoperitoneum. Then, one 10-12 mm trocar was inserted at the right midclavicular line and three 5 $\mathrm{mm}$ trocars at the left midclavicular line, right and left anterior axillary lines under direct vision. A $30^{\circ}$ telescope was used in the operations. At the beginning of the process, the duodenum was mobilized with a Kocher maneuver. First the inferior vena cava and aorta, then the pancreatic head was revealed by opening the gastrocolic ligament. It was seen that the lesion was resectable by mobilization of the pancreatic neck from the SMV and middle colic vein. Antrectomy was made with an endoscopic linear stapler (EchelonFlex ${ }^{\mathrm{TM}}$; Ethicon, USA). Following cholecystectomy, the common bile duct was suspended and then cut. High energy instruments (Harmonic scissors, Ethicon, USA) were used in the division of pancreatic neck. The ligament of Treitz was mobilized, and the fourth part of the duodenum and jejunum were transected with an endoscopic linear stapler (EchelonFlex ${ }^{\mathrm{TM}}$; Ethicon, USA). Resection was completed with standard lymphadenectomy. Following Pfannenstiel mini-incision, the resection specimen was taken out of the abdomen within a container (Endobag ${ }^{\mathrm{TM}}$; Covidien, USA). The Wirsung duct was found in the remnant pancreas and a stent was placed, then retro-colic Wirsung-jejunostomy, hepaticojejunostomy, and gastrojejunostomy anastomoses were made intra-corporeally (Figure 1, 2). Two drains were used, and they were placed next to the pancreas and bile duct anastomosis from the right and left. Intraoperative ultrasound was not used during the operation. AJCC (American Joint Committee on Cancer) and TNM (T tumor, N node, and $\mathrm{M}$ metastasis) criteria were used for postoperative histopathologic and clinical evaluations.

The series consisted of three (60\%) female and two (40\%) male patients. The average age of our patients was 62.8 years (range 51-77). ASA scores were 1 in 2 patients and 2 in 3 patients. All five patients underwent total laparoscopic pancreaticoduodenectomy and intracorporeal anastomosis. Conversion

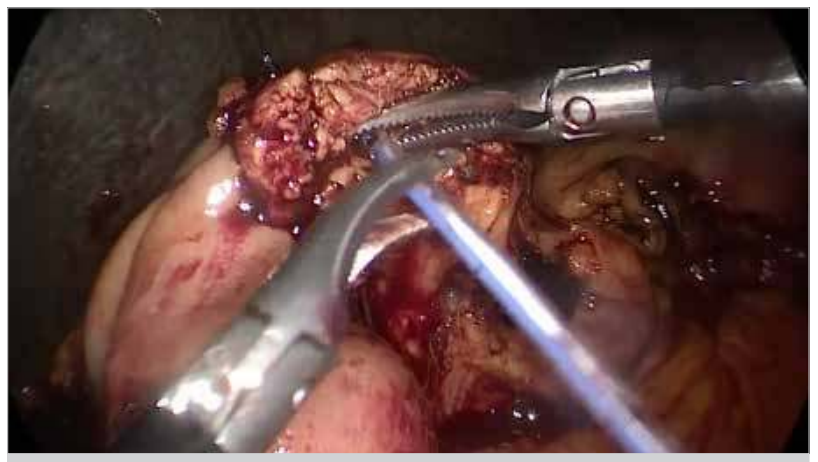

Figure 1. The Wirsung duct was found and placed a stent laparotomy was not made during the operations. The stent was placed in the Wirsung duct of all patients and an end to side Wirsung-jejunostomy was perfromed. No intraoperative complication developed during the procedure. The average Wirsung duct diameter was $6 \mathrm{~mm}(5 \mathrm{~mm}-8 \mathrm{~mm})$, and that of the bile duct was $17 \mathrm{~mm}(15 \mathrm{~mm}-20 \mathrm{~mm})$. The operation lasted approximately 264 minutes (240-300 minutes). There was no pancreatic anastomosis leakage in the patients. Biliary leakage was detected in $2(40 \%)$ patients in the postoperative period. The biliary leakages closed spontaneously on the 7th day in the first patient and the 10th day in the second patient. One mortality occurred (20\%) in a patient following sudden bleeding on the sixth postoperative day. The surgical exploration of this patient revealed that the clips on the gastroduodenal artery were opened, and caused the bleeding. The adenocarcinoma differentiation degree was reported as good in 3 patients and as moderate in 2 patients. Surgical margins were negative in all patients. Patient characteristics, tumor localization, comorbidity presence, total and direct bilirubin values, CEA and CA 19-9 values, surgical tumor diameter, bile duct and Wirsung duct diameters are presented in Table 1. The blood loss during operation, operation duration, tumor characteristics, lymph node metastasis, length of hospital stay, morbidity and mortality rates are also presented.

\section{DISCUSSION}

Minimal invasive surgical procedures were initially used for staging and palliation in pancreas surgery followed by radical resections (4). Retroperitoneal localization of the pancreas gland and its close relationships with the duodenum and mesenteric-portal vascular structures restrict minimal invasive attempts due to technical difficulties in intracorporeal anastomosis (two-dimensional camera, hand tools with limited mobility and independent mobility of the devices - fulcrum effect) and critical postoperative complications.

Patient selection is critical for a successful procedure. Laparoscopic resection is recommended for small, benign or lowgrade pancreas head, duodenal ampulla, and distal biliary duct tumors as long as there is no vascular and extra-biliary spread $(3,5)$. Especially, lesions without major artery and vein involvement, those localized in the pancreatic uncinate and neck part or ampullary lesions, mucinous cystic neoplasms and intra-papillary mucinous neoplasms (IPMNs) are ideal for laparoscopic resection.

Laparoscopic intracorporeal anastomosis, mini-laparotomy or hand-port techniques have been used in laparoscopic resec-

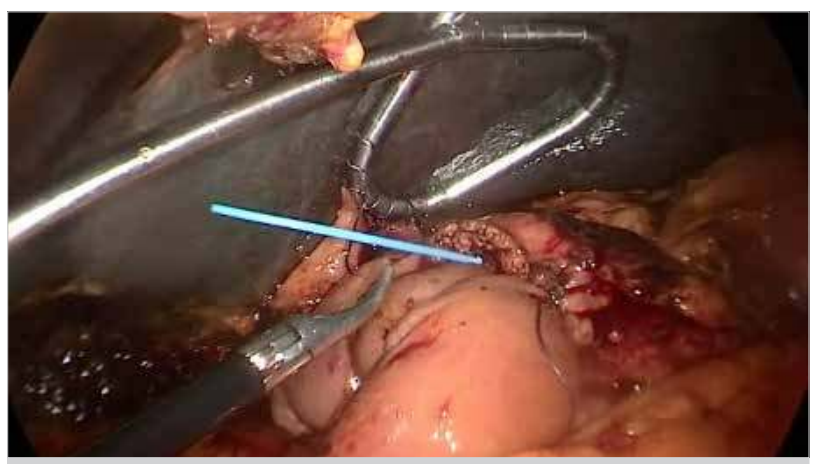

Figure 2. Retro-colic Wirsung-jejunostomy 
tion and reconstruction (6). A review of the literature showed that after the first laparoscopic pancreaticoduodenectomy in 1994, resection was perfromed in 746 cases; complete laparoscopic resection and anastomosis in 386 (51.7\%) patients, robotic resection and anastomosis in 234 (31.3\%) patients, laparoscopic resection and anastomosis with mini-laparotomy in $121(16.2 \%)$ patients, hand-assisted resection and anastomosis in $5(0.6 \%)$ patients (7).

In patients who underwent complete laparoscopic resection it was detected that; biliary leakage rate was $2.4-7 \%$, average blood loss was $65-240 \mathrm{cc}$, the rates of delay in gastric emptying was reported as $7-9.1 \%$, bowel obstruction as $6.2 \%$, intraabdominal bleeding as $5.3 \%$, intraabdominal abscess development as $2.4 \%-19.9 \%$, wound infection as $11.3 \%$, and pulmonary complications and deep vein thrombosis (DVT) as $2.4 \%-14.3 \%$ (3). The start of bowel movements was determined as about 4 days and the average length of hospital stay was between 8-18 days (8). Similar operative time (268 minutes and 286 minutes), blood loss (75 cc or $83 \mathrm{cc}$ ), complication rate (33\% and $25 \%$ ) and length of hospital stay (13.4 days and 14 days) were detected in laparoscopic and hybrid methods (9). After laparoscopic resections, a lower rate of delay in gastric emptying and surgical site infection were seen as compared to open surgery (10). Conversion rate from laparoscopy to open surgery changes between $0 \%$ and $31.6 \%$ (11). Operation times were longer than 7 hours in the initial laparoscopic surgeries. On the other hand, with experience, operation and hospitalization times became shorter and blood loss was reduced during the operation (5). There was no delay in gastric emptying, any pulmonary complications, or DVT in our patients. Although biliary leakage was detected in two patients, they closed spontaneously. Bleeding occurred in one patient that resulted in mortality.

It is shown that laparoscopic minimal invasive procedures provide equivalent short-term oncologic results to open sur- geries. R0 resection and sufficient lymph node dissection can be achieved via laparoscopic pancreaticoduodenectomy; 15 lymph nodes on average (minimum 7 , maximum 36 ) are reported to be extracted after resection, and the positive margin was $0.4 \%(3,10)$. In studies on laparoscopic pancreaticoduodenectomy, usually low grade $(2.1-3 \mathrm{~cm})$ patients without major vascular involvement are selected. Negative surgical limits are achieved in $100 \%$ of laparoscopic procedure while $\mathrm{R} 0$ resection could be obtained in $70-80 \%$ in open surgery. This difference is attributed to patient selection criteria in laparoscopic attempts (12). The two-year survival rate is found as $36 \%$ after open surgery, and $43 \%$ after laparoscopic surgery (13).

Postoperative morbidity rate is reported as $25-48 \%$ for laparoscopic resections, and $31 \%$ for open resections (12). Pancreas fistula is a significant problem in the postoperative period. ISGPF (International Study Group of Pancreatic Fistula) specifies grade B pancreatic fistula rate between $2.4-18 \%$, which is similar to open surgery $(3-13 \%)(5,8)$. In addition to the anastomosis technique, the consistency of the remnant pancreas tissue is quite critical. A soft remnant pancreas tissue is an important risk factor for fistula development (14). There was no pancreatic anastomotic leakage in our patients. This was probably related to the low patient number in the series and to the anastomotic technique of Wirsung duct to jejunum mucosa anastomosis over a stent that has been used. The mortality rate varies between $1.9-5.7 \%$ in the first postoperative month (8). Pulmonary complications, difficulties in early mobilization, deep venous thrombosis, intraabdominal abscess and bleeding, anastomotic problems and vascular injury were the reasons of post-operative mortality (15). In our study, one patient died due to gastro-duodenal artery bleeding on the $6^{\text {th }}$ post-operative day.

Although the number of patients is low and the follow-up period is short in our study, we think that radical pancreas surgery with laparoscopic method contains similar risks with

Table 1. Patient demographic, clinical and histopathologic data

\begin{tabular}{|c|c|c|c|c|c|}
\hline & $1^{\text {st }}$ Patient & $2^{\text {nd }}$ Patient & $3^{\text {rd }}$ Patient & $4^{\text {th }}$ Patient & $5^{\text {th }}$ Patient \\
\hline Age (year) & 77 & 74 & 51 & 59 & 53 \\
\hline Sex & $\mathrm{F}$ & $\mathrm{F}$ & $M$ & M & $M$ \\
\hline Comorbidity & HT & HT & - & DM & - \\
\hline Total-Direct Bilirubin (mg/dL) & $3.7-3.03$ & $0.68-0.28$ & $3.07-2.43$ & $9.12-7.19$ & $9.27-6.51$ \\
\hline CEA-CA 19.9 (ng/mL) & $0.87-313$ & $2.7-41$ & $9.56-4142$ & $10.48-700$ & $1.28-288$ \\
\hline Tumor Diameter (mm) & 30 & 25 & 20 & 36 & 30 \\
\hline Common bile duct Diameter (mm) & 15 & 15 & 20 & 15 & 20 \\
\hline Wirsung duct Diameter (mm) & 5 & 5 & 8 & 7 & 5 \\
\hline Operation Time (minute) & 240 & 240 & 300 & 240 & 300 \\
\hline Length of hospital stay (day) & 8 & 8 & 10 & 6 & 16 \\
\hline Lymph Node Metastasis & $1 / 12$ & $0 / 12$ & $0 / 11$ & $0 / 13$ & $0 / 12$ \\
\hline Morbidity & - & - & Bile leakage & - & Bile leakage \\
\hline Mortality & - & - & - & + & - \\
\hline
\end{tabular}


the conventional method. Despite the technical difficulties of laparoscopic pancreaticoduodenectomy and its requirement of a learning curve, it may be applied to selected patients as an alternative to open surgical procedures, in centers with necessary equipment and experience in laparoscopic resections, due to its less blood loss, the improvement in gastric emptying, early discharge from hospital, and return to work advantages. Well-planned studies with a high number of patients are needed to evaluate long-term oncologic results.

Informed Consent: Written informed consent was obtained from patients who participated in this study.

Peer-review: Externally peer-reviewed.

Author Contributions: Concept - H.A.K.; Design - H.M.Ç.; Supervision - U.E.E.; Resource - H.M.Ç.; Materials - H.M.Ç.; Data Collection and/or Processing - H.M.Ç., E.D., M.E.B.; Analysis and/or Interpretation - H.A.K., H.M.Ç., E.D.; Literature Search - H.M.Ç., U.E.E., E.D., M.E.B.; Writer Manuscript - H.A.K., H.M.Ç., E.D.; Critical Review U.E.E., M.E.B.

Conflict of Interest: The authors have no conflicts of interest to declare.

Financial Disclosure: The authors declared that this study has received no financial support.

\section{REFERENCES}

1. Siegel R, Naishadham D, Jemal A. Cancer statistics, 2013. CA Cancer J Clin 2013; 63: 11-30. [CrossRef]

2. Bilimoria KY, Bentrem DJ, Ko CY, Stewart AK, Winchester DP, Talamonti MS. National failure to operate on early stage pancreatic cancer. Ann Surg 2007; 246: 173-180. [CrossRef]

3. Ammori BJ, Ayiomamitis GD. Laparoscopic pancreaticoduodenectomy and distal pancreatectomy: a UK experience and a systematic review of the literature. Surg Endosc 2011; 25: 2084-2099. [CrossRef]

4. Gagner M, Palermo M. Laparoscopic Wipple procedure: review of the literature. J Hepatobiliary Pancreat Surg 2009; 16: 726-730. [CrossRef]
5. Kendrick ML, Cusati D. Total laparoscopic pancreaticoduodenectomy: feasibility and outcome in an early experience. Arch Surg 2010; 145: 19-23. [CrossRef]

6. Lee JS, Han JH, Na GH, Choi HJ, Hong TH, You YK, Kim DG. Laparoscopic pancreaticoduodenectomy assisted by mini-laparotomy. Surg Laparosc Endosc Percutan Tech 2013; 23: 98-102. [CrossRef]

7. Boggi U, Amorese G, Vistoli F, Caniglia F, De Lio N, Perrone V, et al. Laparoscopic pancreaticoduodenectomy: a systematic literature review. Surg Endosc 2015; 29: 9-23. [CrossRef]

8. Asbun HJ, Stauffer JA. Laparoscopic vs open pancreaticoduodenectomy: overall outcomes and severity of complications using the Accordion Severity Grading System. J Am Coll Surg 2012; 215: 10-819. [CrossRef]

9. Dulucq JL, Wintringer P, Stabilini C, Feryn T, Perissat J, Mahajna A. Are major laparoscopic pancreatic resections worthwhile? A prospective study of 32 patients in a single institution. Surg Endosc 2005; 19: 1028-1034. [CrossRef]

10. Gumbs AA, Rodriguez Rivera AM, Milone L, Hoffman JP. Laparoscopic pancreatoduodenectomy: a review of 285 published cases. Ann Surg Oncol 2011; 18: 1335-1341. [CrossRef]

11. Kuroki T, Adachi T, Okamoto T, Kanematsu T. A nonrandomized comparative study of laparoscopy-assisted pancreaticoduodenectomy and open pancreaticoduodenectomy. Hepatogastroenterology 2012; 59: 570-573. [CrossRef]

12. Sohn TA, Yeo CJ, Cameron JL, Koniaris L, Kaushal S, Abrams RA, et al. Resected adenocarcinoma of the pancreas-616 patients: results, outcomes, and prognostic indicators. J Gastrointest Surg 2000; 4: 567-579. [CrossRef]

13. Kendrick ML. Laparoscopic and robotic resection for pancreatic cancer. Cancer J 2012; 18: 571-576. [CrossRef]

14. Berger AC, Howard TJ, Kennedy EP, Sauter PK, Bower-Cherry M, Dutkevitch $S$, et al. Does type of pancreaticojejunostomy after pancreaticoduodenectomy decrease rate of pancreatic fistula? A randomized, prospective, dualinstitution trial. J Am Coll Surg 2009; 208: 738-747. [CrossRef]

15. Çakır M, Küçükkartallar T, Tekin A, Tuncer FB, Kartal A. Bile duct ischemia developing after reconstruction of the hepatic artery during the Whipple operation. Ulus Cerrahi Derg 2015; 31: 235237. 